\title{
Innovative development of socio-technical systems
}

\author{
Tatiana Moiseeva, , and Yuri Myatishkin
}

Samara Federal Research Scientific Center RAS, Institute for the Control of Complex Systems RAS, Sadovaya Str., 61, 443020 Samara, Russia

\begin{abstract}
Modern management of socio-technical systems is based on the principles of the classical ideal bureaucracy of Max Weber, formed many decades ago. Among the historically inherited problems of modern management, corresponding to the traditional development of sociotechnical systems, the decisive factor is the bias towards the formalization of management. A person with untapped potential is pushed out of the management system. The subject is depersonalized and placed on a par with other elements of the model. This approach underlies the development of socio-technical systems, which can be called traditional. Innovative development requires the use of new management methods to unleash the potential of people. Among the subject-oriented approaches to management, we should underline the theory of intersubjective management, proposed by V.A. Vittikh. It could complement traditional management.
\end{abstract}

\section{Introduction}

Modern socio-technical systems have formed management systems. Their formation has continued since the inception of management. The relationship between the managing subsystem and the managed one is based on traditional approaches to management, when decisions are made by managers of different levels. Employees of socio-technical systems put these decisions into practice, but managers are responsible for them [1-4]. As a result, decisions turn out to be depleted due to underestimation of the opinions of performers who see other facets of problems, and the implementation of the decisions is far from perfect due to the fact that performers do not take responsibility for the work done.

The innovative development of a socio-technical system means the use of other approaches to management. The main directions of the search for new ways of management development are associated with the study of the capabilities of people, their subjective and personal characteristics [5-7]. However, the promotion of new approaches is complicated by the fact that it meets the resistance not only from the top management of enterprises, but from the ordinary staff too.

\footnotetext{
*Corresponding author: mtv-2002@yandex.ru
} 
Therefore, let's consider what factors corresponding to the traditional development of socio-technical systems are inherited by modern management in order to understand how they can be overcome in the process of adopting innovative approaches.

\section{Materials and methods}

The materials for this paper are the works of famous scientists in the field of management. The research methods are theoretical analysis and synthesis based on formal logic, and diachronic analysis.

\section{Results and discussion}

\subsection{Problems of modern management of socio-technical systems}

Among the historically inherited problems of modern management, corresponding to the traditional development of socio-technical systems, let's note the following (Fig. 1).

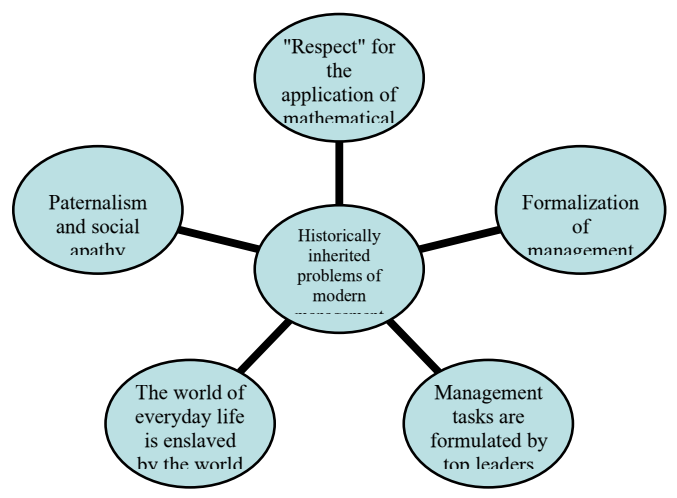

Fig. 1. Historically inherited problems of modern management.

1. "Respect" for the application of mathematical methods and models for solving management problems and making decisions. As a result, such approach obscures the real system from the researcher. He begins to work with its model, looking for an optimal management and decision-making in the model he is investigating. So, the questions arise, if this simulated model can be adequate the model of the real system, and how this model can be legitimate. The researcher really can't see the dependence and influence of the cause and effect between initial data "from life" and the solutions of the studied problems made by him. How can we trust such a result if the management problem was solved for a certain model of the socio-technical system? This model was found suitable under the assumption that the parameters of the model correspond as much as possible or closely enough to the real system. But the situation in life differs from the model or the researcher could not have noticed all the nuance of the environment. It turns out that the decision was made to solve the management problem for the wrong socio-technical system.

2. Formalization of management processes, overshadowing a living person with undisclosed potential. The subject is depersonalized and put on a par with other elements of the model, which corresponds to the bureaucratic approach to management, when it turns out to be more convenient to deal with a certain projection of a person in a socio-technical 
system, using a generalized model and highlighting formal parameters inherent in all elements, and not special ones, unique and characteristic only for this person.

3. Formulation of tasks by leaders at the upper levels of the management hierarchy. We are sure that no harm is done if management tasks are formulated by leaders and not by employees of socio-technical objects. But is there a catch in the fact that participants of the management processes involved in problem situations (and it can be entire team of the socio-technical system) have to fulfil the solutions made by other not involved people?

Modern traditional practice of management in society boils down to the activities of managers of different levels giving them the power not only to take control of the processes of implementation of decisions made by them (and responsibility for them), but they also empowered to set the tasks related to finding solutions and solving problem situations. Despite the fact that experts in different fields are involved in management processes, the most important thing is assigned to the leaders. They have the exclusive right to make a decision and answer the question, what needs to be done. They also estimate the results of solving problem situations in practice. This approach to management creates a contradiction: people who are aware of themselves in a problem situation, "living" it, are engaged in the implementation of the manager's decisions in order to subsequently take advantage of the results that do not reflect their own views on the problem and ways to solve it. The rejection of the participants in problem situations from making decisions to find a way out of them cannot bring people the desired relief, does not make it possible to use all their inner potential to implement "other people's" decisions, and in some cases creates a critical situation due to accumulating dissatisfaction.

4. The world of everyday life is enslaved by the world of systems, when bureaucratic structures dictate their own conditions, the implementation of which distorts the meaning originally invested in the activities performed. The formation of the governing influence by the governing bodies from the world of systems leads to a decrease in the effectiveness of management in situations where the performers themselves can adequately assess the problem, being able to offer optimal options for its solution. This practice of the traditional approach to the organization of complex systems management processes is based on classical scientific ideas of systems management, which don't take into account the subjective characteristics of people, their cultural and value priorities, systems of views, intellectual abilities, and many other features of a person. It means that a multidimensional personality from everyday life, become its flat projection from the systems world.

5. Paternalism and social apathy in society and socio-technical systems emerge from traditional approaches to management. People think that they are not much of a trier and will not be able to contribute to decision-making on important issues for them. Their great potential stay undetected, because they are sure that nothing will be done and they do not have such a right. Needless to say, that times change. Now the worker is interpreted not only as a mechanical force transforming matter from one form to another. Creative person is becoming an economic subject.

Mentioned above problems of modern management forces to look for new mechanisms for managing the development of society. Traditional approach to management causes discontent among members of socio-technical systems. It takes place because of our inability to create an organizational structure at the level of the whole society that would allow us to effectively solve problems. It doesn't concern insufficient level of knowledge or abilities of individuals. Most of the measures implemented today at the high levels of management are aimed at creating and maintaining of administrative-command system of management. The decisions are made by the officials and bureaucrats.

New means corresponding to the innovative development of socio-technical systems are needed to change management. It should largely rely not on decisions made "at the top ", but on the actions coming from " below." 


\subsection{Innovative development of socio-technical systems}

Determination of strategies and possible directions for transformation of complex systems affects humanistic values, therefore, the management of "human-sized" socio-technical systems not only allows, but also presupposes the use of an axiological approach, which is based on the value perception of social reality and universal principles.

Post-nonclassical scientific rationality takes into account that any human action in socio-technical systems is not an external factor in relation to the system, but an internal one, being included in it and making irreversible changes in the field of its possible states.

We can say that the conceptual basis of innovative development management is determined by the philosophical understanding of post-nonclassical scientific rationality. The main provisions of this modern type of scientific rationality make us to understand management not as "hard" forms that imply the determination of systems, but "soft" ones that determine the creation of conditions for their development.

The subjectivation of science requires a rethinking of many problems, among them is the problem of including a person in management processes. And the methodology of postnonclassics is based on a subject-oriented approach as the leading one in scientific research and in practical applications. Increasing attention to subjects in the context of the development of scientific rationality ideas is a distinctive feature of progressive management concepts (both at the micro- and macro-levels), requiring the use of special socio-humanitarian technologies today.

The relevance of the application of the "subject - subject" paradigm in the sociotechnical systems management is confirmed by the fact that the works of such Nobel Prize winners of the XXI century in economics as Daniel Kahneman, Vernon Lomax Smith, Elinor Ostrom, Oliver Williamson, who are noted as having made a significant contribution to its formation, are devoted specifically to subject-oriented topics [8-11]

Despite the fact that in real life there is still a wary attitude towards subjectivity itself as an expression of distrust towards a person as the subject of choice and the decisions made by him, in Russian and international management theory, the emphasis is made on the need to apply a subject-oriented approach, especially in the context of innovative development by socio-technical systems. Social processes today are studied not only by modern sociology, but also by management and economics.

The statement that social changes concerning the interaction, negotiation and mediation of people in management processes are no less important than technical and technological ones is adopted by the part of scientific and the human communities. Moreover, the participants jf management processes are people and public organizations of citizens involved in social problems. And they must be welcome to make decisions and develop mechanisms for solving global and local problems. Active involvement in decision-making processes of all participants in public relations with a significant increase in the role of individual social groups, associations and leaders representing the interests of the population, creating conditions for innovative development is one of the patterns of evolution and development of socio-technical systems[12].

We can say that the innovative development of socio-technical objects today is associated with new management decisions based on decision-making mechanisms that are different from those used previously, and implies improvements in people's lives (which meets the social needs of people). The innovative development of socio-technical systems is possible with the application of such a management paradigm, which would be based on post-non-classical scientific rationality, using a subjective approach focused on the real consideration of the human factor in management. Therefore, as a concept of innovative development of socio-technical systems, it is proposed to use the theory of intersubjective management proposed by V.A. Vittikh [13-16]. 
Among the modern management concepts that have made themselves known since the 2000 s and claiming to be a new subject-subject mainstream in cybernetics (for example, The Science of Cybernetics of Umpleby S. [17] or Sociocybernetics of Mancilla R. and Kenny V. [18]), the theory of V.A. Vittikh has such peculiarities:

society;

only this theory is aimed at resolving the problem situations of people in

- decisions about a problem situation solving are made by the actors themselves, immersed in this situation and feeling it in a completely different way than people who observe and cognize the situation from the outside, for example, managers in sociotechnical systems.

Considering that the genesis of modern innovative development has not yet been sufficiently studied, and there is no relevant theory, we propose to supplement the traditional management, adopted in most socio-technical systems, with an intersubjective approach.

The approach to the study of management processes, implemented on the principles of post-nonclassical scientific rationality, leads to the need of revising the traditional concepts of management. Therefore, intersubjective management, on the one hand, is opposed by V.A. Vittikh to classical management based on the principles of the ideal bureaucracy of M. Weber, and on the other hand, it is intended to supplement it.

\section{Conclusions}

1. The traditional development of socio-technical systems is based on a set of historically formed factors. Among them it is necessary to highlight the following:

- $\quad$ "respect" for the use of mathematical methods and models for solving problems of management and decision-making;

- formalization of management processes, depersonalizing a person;

- alienation of the management object from the management process;

- paternalism and social apathy in society, etc.

2. The innovative development of socio-technical systems means the use of new approaches to management. The subject-oriented approach is designed to overcome these barriers of traditional management.

3. Among the subject-oriented approaches known today, the theory of intersubjective management proposed by V.A. Vittikh, is aimed at problem situations solving.

4. Supplementing classical management with the theory of intersubjective management will make it possible to use the potential of actors in socio-technical systems.

\section{Acknowledgments}

The paper was prepared according to the plan of research work of Samara Federal Research Scientific Center RAS, Institute for the Control of Complex Systems RAS, theme No. AAAA-A19-119030190053-2.

\section{References}

1. P.F. Drucker, The Practice of Management (1954)

2. S. Milgram, Obedience to Authority (1974)

3. M. Weber, The Theory of Social and Economic Organization (1947)

4. J. Woodward, Industrial Organization (1965) 
5. T.V. Moiseeva, Proc. XXI Int. Conf. "Complex Systems: Control and Modeling Proble ms" (CSCMP 2019), 765 (2019)

6. T.V. Moiseeva, S.V. Smirnov, Studies in Systems, Decision and Control, 199, 15 (2019)

7. T.V. Moiseeva, Proceeding of the International Science and Technology Conference "FarEastCon 2019", 267 (2019)

8. D. Kahneman, T. Gilovich, D. Griffin, Heuristics and Biases: The Psychology of Intuitive Judgment (2002)

9. V. L. Smith, American Economic Review, 72 (5), 923 (1982)

10. E. Ostrom, Governing the Commons: The Evolution of Institutions for Collective Action (1990)

11. O. E. Williamson, J. of Economic Perspectives, 16 (3), 171 (2002)

12. M. Kotsemir, D. Meissner, Conceptualizing the Innovation Process (2013) https://wp.h se.ru/

13. V. A. Vittikh, Group Decision and Negotiation, 24(1), 67 (2015)

14. V. A. Vittikh, Group Decision and Negotiation, 24(5), 825 (2015)

15. V. A. Vittikh, Group Decision and Negotiation, 24(6), 949 (2015)

16. V. A. Vittikh, Int. J. Management Concepts and Philosophy, 9(2), 63 (2016)

17. S. Umpleby, Cybernetics and Systems, 21(1), 109 (1990)

18. R. Mancilla, J. of Sociocybernetics, 42(9), 35 (2011) 